\title{
ELECTROLYTIC PRECIPITATION OF BRONZES
}

\section{BY B. E. CURRY}

It is commonly supposed that it is difficult to precipitate good bronze electrolytically. For this reason the general method for preparing bronze plate is to precipitate a brass and bronze it by chemical methods. ${ }^{1}$

The best brass is precipitated from cyanide solutions. Because of the slight solubility of the cyanide of tin this solution can not be employed for the deposition of bronze.

Brass cannot be precipitated satisfactorily from ordinary salt solutions. The tendency for the copper to precipitate first causes the solution to concentrate continually with respect to the zinc and at the same time to become poor in copper. When the ordinary salt solutions of copper and tin are electrolyzed the copper precipitates first and the solution becomes rich in tin. For this reason the more common electrolytes cannot be used for a continuous precipitation of bronze.

Since the ordinary salt solutions are not satisfactory for the deposition of bronze it was thought advisable to try some solution in which both copper and tin form soluble double salts. In selecting an electrolyte the behavior at the anode as well as at the cathode must be considered. It has already been shown that over a considerable range the bronzes dissolve quantitatively ${ }^{2}$ in both alkaline tartrate and acid ammonium oxalate solutions.

Some tests with the alkaline tartrate solutions showed these to be undesirable. A satisfactory bronze could not be obtained and the solution changed continually in concentration. In the presence of the stannous salts the copper was thrown from solution and deposited on the walls and bottom of the containing vessel. For these reasons the tartrate solution was abandoned.

${ }^{1}$ Watt and Philip: Electroplating of Metals, 308.

2"Electrolytic Corrosion of the Bronzes," Jour. Phys. Chem., Io, 487. 
Some preliminary tests with acid ammonium oxalate solutions produced a good bronze. Experience has shown that this solution must be prepared with a considerable amount of care. If the acid content is made too high, the copper is precipitated as an insoluble salt. When the acid content is too low or the solution slightly alkaline, the tin becomes insoluble. At ordinary temperatures about 7 percent oxalic acid forms a saturated solution; the ammonium salt is a little less soluble.

It was noted early in the work that there was a wide difference between the composition of the deposited bronze and the relative amounts of copper and tin in solution. In order to determine the composition of the solution and that of the bronze the following stock solutions were prepared:

\begin{tabular}{|c|c|c|c|c|}
\hline $\begin{array}{l}\text { Grams } \\
\mathrm{H}_{2} \mathrm{C}_{2} \mathrm{O}_{4}\end{array}$ & $\begin{array}{c}\text { Grams } \\
\left(\mathrm{NH}_{4}\right)_{2} \mathrm{C}_{2} \mathrm{O}_{4}\end{array}$ & $\begin{array}{c}\text { Grams } \\
\mathrm{CuSO}_{4} 5 \mathrm{H}_{2} \mathrm{O}\end{array}$ & $\begin{array}{c}\text { Grams } \\
\mathrm{SnC}_{2} \mathrm{O}_{4}\end{array}$ & $\begin{array}{c}\mathrm{cc} \\
\mathrm{H}_{2} \mathrm{O}\end{array}$ \\
\hline 5 & 55 & - & I 8 & 1000 \\
\hline 5 & 55 & I 5 & - & 1000 \\
\hline
\end{tabular}

From these, two series of solutions were made up with known amounts of copper and tin varying in shifts of Io percent. It will be noted that these solutions are different from the solutions in which the corrosion experiments were made inasmuch as they contain sulphates. The presence of sulphates or chlorides is necessary in order to keep the copper in solution. One of these series was electrolyzed with a 90 percent copper anode and the other with an 80 percent anode. In each case about 0.3 gram of bronze was deposited, weighed, and then analyzed. The anodes were weighed before and after each run. In this way a check was had on the composition of the solution at the end of the run. In runs of this length the total change in the concentration of the copper and tin in solution was not great. Corrections were calculated for this and the results plotted in Fig. r. Here the coordinates are percentage copper in solution and percentage copper in the precipitated bronze. As the curve indicates that there is a wide 
difference between the composition of the solution and of the precipitated bronze, the curve also indicates that the lowest copper content an electrolytic bronze can have is about 78 percent. However, when a 75 percent copper anode is used a fairly good bronze with 75 percent copper content can be

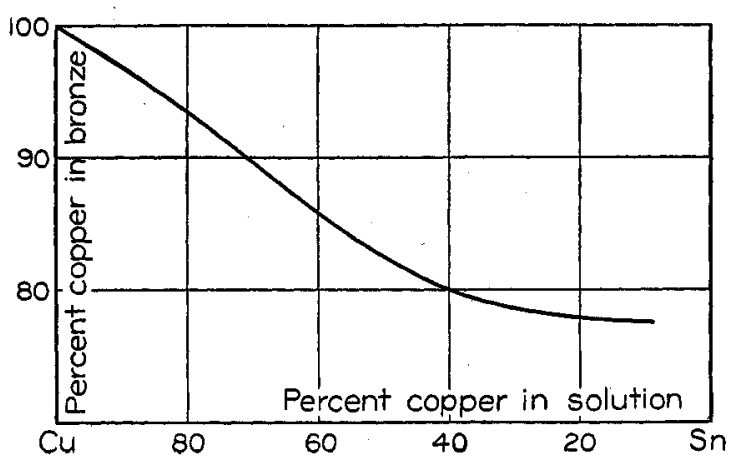

Fig. 1

obtained. When the copper content in solution becomes as low as Io percent of the total amount of copper and tin in solution some care is necessary to prevent the deposit from becoming black and spongy. Also the composition is likely to vary.

In these runs the anodes were cast in the form of plates with a surface on one side of about $40 \mathrm{~cm}^{2}$. The cathodes were platinum discs with a surface of $30 \mathrm{~cm}^{2}$. The cathodes were rotated and in this way the solutions kept well stirred and the deposit remained bright and smooth. If the solutions are not stirred the deposits blacken very quickly. If the anodes remain stationary there is some tendency for slimes to form but this is not great:

" In order to show more conclusively that the curve in Fig. I represents the facts obtained in longer runs, solutions containing relatively 82.5 percent, 70 percent and 60 percent copper were electrolyzed with 95 percent, 90 percent and 85 percent copper anodes respectively. The anode density was 0.3 ampere per $\mathrm{dm}^{2}$ and the cathode density 0.2 ampere per $\mathrm{dm}^{2}$. In this case the cathodes were cast in the form of cyl- 
inders and both cathode and anode were rotated. At the end of the run both the anode and cathode were bright and clean. The results are given in Table $I$.

TABLE I

\begin{tabular}{c|c|c|c|c}
\hline $\begin{array}{c}\text { Percent } \mathrm{Cu} \text { in } \\
\text { anode }\end{array}$ & $\begin{array}{c}\text { Percent } \mathrm{Cu} \text { in } \\
\text { solution }\end{array}$ & $\begin{array}{c}\text { Anode loss in } \\
\text { grams }\end{array}$ & $\begin{array}{c}\text { Wt. of bronze } \\
\text { in grams }\end{array}$ & $\begin{array}{c}\text { Percent } \mathrm{Cu} \\
\text { in bronze }\end{array}$ \\
\hline 95 & 82.5 & 3.44 & $3.5 \mathrm{I}$ & 94.7 \\
90 & 70.0 & 2.70 & 2.52 & 89.5 \\
85 & 60.0 & 3.08 & 2.90 & 86.5 \\
\hline
\end{tabular}

At the end of the runs about 0.3 gram of the bronze was deposited on clean electrodes and analyzed. In the solutions which were electrolyzed with 95 percent and 90 percent copper electrodes the solutions were practically unchanged. The 85 percent anode became tin-rich on the surface and for this reason the concentration of the solution and deposited bronze shifted slightly. The bronzes with a copper content varying between 74 percent and 87 percent are composed of two phases, the $\alpha$-phase rich in copper and the $\delta$-phase rich in tin. In oxalate solutions containing sulphates the $\alpha$-phase tends to dissolve first and the surface of the anode becomes rich in $\delta$-crystals. Between 87 percent and pure copper the bronzes have but one form of crystallization and dissolve uniformly without change.

A second series of runs was made with copper chloride substituted for the copper sulphate in the original solution. The chlorides do not interfere with the cathode reaction in any way. The results are given in Table II.

TABLE II

\begin{tabular}{c|c|c|c|c}
\hline $\begin{array}{c}\text { Percent Cu in } \\
\text { anode }\end{array}$ & $\begin{array}{c}\text { Percent Cu in } \\
\text { solution }\end{array}$ & $\begin{array}{c}\text { Anode loss in } \\
\text { grams }\end{array}$ & $\begin{array}{c}\text { Weight of } \\
\text { bronze in grams }\end{array}$ & $\begin{array}{c}\text { Percent Cu } \\
\text { in bronze }\end{array}$ \\
\hline 85 & 60 & $2.0 \mathrm{I}$ & 2.37 & 85.5 \\
80 & 49 & 2.38 & 2.00 & $8 \mathrm{I} .2$ \\
\hline
\end{tabular}

These anodes dissolve without change and the tendency to dissolve tin-rich did not appear as in the solutions containing sulphates. 
In these longer runs the deposits remained bright but became rough and pitted toward the end.

Some experiments were made with a high current density at the anode to determine the effect on the solubility. With a current density of one ampere per square decimeter the anodes containing more than 87 percent copper dissolved uniformly and with a good efficiency. With less than 87 percent copper at the higher current densities the tendency for the anodes to become tin-rich was more apparent. The current density at the cathode can vary over a considerable range and the deposit remain satisfactory. Good deposits were obtained with a current density varying from 0.2 ampere to 2 amperes per square decimeter.

When cast bronzes with more than 87 percent copper are annealed below $500^{\circ} \mathrm{C}$ they are homogeneous under the microscope. There is but one form of crystallization over this range. These crystals are designated as $\alpha$. The bronze with 74 percent copper is also homogeneous and this particular form of crystallization is designated as $\delta$. Over the range between 74 percent and 87 percent copper the bronzes are not homogeneous but show a mixture of $\alpha$-and $\delta$-crystals.

It is certain that the electrolytic bronzes are deposited under equilibrium conditions. All of these appear homogeneous under the microscope when the copper content is above 90 percent. The 76 percent copper bronze is almost homogeneous but there is evidence of a small amount of a second phase. The 83 percent bronze shows two phases in almost equal amounts.

The electrolytic bronzes with more than 88 percent of copper bend readily, but with a less amount of copper the bronze begins to harden and break when bent. These do not dissolve readily in nitric acid. The electrolytic bronzes correspond closely in color and general appearance to the cast bronzes over the same range of composition. 
The best plating solution for bronzes should contain about 5 grams of free oxalic acid and 55 grams of ammonium oxalate per Iooo cc of water. The relative amounts of copper and tin in solution may be shifted in any ratio depending on the composition of the plates desired. The cathode should be rotated if possible.

The presence of chlorides is preferable to large amounts of sulphates.

It has been found to be very difficult to precipitate a good bronze with less than 75 percent copper content.

A low current density at the cathode is necessary.

The anode dissolves better when rotated.

The electrolytic bronzes represent equilibrium conditions.

This work has been carried on under a grant from the Carnegie Institution to Professor Bancroft.

Cornell University, May, ıgo6. 